\title{
Comparative Perspectives on Social Indicators
}

\author{
Sandra Fachelli ${ }^{1,2} \cdot$ Pedro López-Roldán ${ }^{3}$
}

Published online: 2 January 2021

(c) The Author(s), under exclusive licence to Springer Nature B.V. part of Springer Nature 2021

\section{Introduction to the Special Issue}

One of the challenges of social research when we construct objects of knowledge is comparative analysis among countries. International comparative research of diverse territorial realities, whether at the macro-social or micro-social level, is fundamental if we are to assess, deepen and improve our knowledge of social phenomena and draw conclusions with theoretical, methodological and empirical implications. The spatial specificity of social dynamics immersed in a temporal, socio-historical and cultural context obliges us to reflect on this comparability. The need to establish generalisations to construct theoretical models of social behaviour that transcend the singularity of a particular territorial reality means we must offer well-founded theoretical-methodological research proposals.

Our proposal in this Special Issue is to address comparative research in the study of social reality, focusing on the construction and use of social indicators in such research among countries (including comparisons between regions or cities). We started out on this path in the context of the European INCASI $^{1}$ project that we had the opportunity to run between 2016 and 2019 together with 20 European and Latin American universities. It gave us the chance to exchange ideas and receive interesting contributions through the Research Committee 55 "Social Indicators" at various international meetings: the ISA Congress in July 2018 (Toronto, Canada) and the Mid-term Conference of the RC55 in the context of the 13th Spanish Congress of Sociology, in July 2019 (Valencia, Spain).

This special issue describes the journey so far, and one that we are determined to continue through the analysis and study of contributions from a wide variety of researchers that have generated theoretical-methodological reflections with a clear comparative focus

\footnotetext{
${ }^{1}$ INCASI is the acronym of "International Network for Comparative Analysis of Social Inequalities" (https ://incasi.uab.cat/en).
}

Sandra Fachelli

sfachelli@upo.es

Pedro López-Roldán

Pedro.Lopez.Roldan@uab.es

1 Departamento de Sociología, Universidad Pablo de Olavide, Seville, Spain

2 Grup de Recerca en Educació i Treball, Universitat Autònoma de Barcelona, Barcelona, Spain

3 Centre d'Estudis Sociològics sobre la Vida Quotidiana i el Treball, Universitat Autònoma de Barcelona, Barcelona, Spain 
(i.e. measurement and study of the same phenomena in different countries) and with wellestablished empirical bases.

\section{On indicators and Comparative Methods}

In terms of social indicators, the broad legacy of the social sciences was to a greater extent collected and transformed during the post-war period by international organisations such as the United Nations and several of its specialised agencies, including UNESCO, the International Labour Organization (ILO), the World Health Organization (WHO) and others, as well as the World Bank, the European Union, the Economic Commission for Latin America and the Caribbean (CEPAL) and the Organization for Economic Cooperation and Development (OECD), among many other institutions, who focused on different objectives sought to standardise measures to address the various phenomena.

Our work focuses more on an academic perspective by comparatively analysing the most relevant contributions from both classical authors and current research on the subject. Hantrais' work (2009) is a good reference for identifying the different contributions, along with their emphasis on and internal discussions of the comparative perspective in different disciplines: sociology, political science, anthropology, education, law, communication, etc.

In a globalised world, local views must be linked to global views. Social phenomena are increasingly interdependent and the "us/them" dichotomy is blurred in global realities and in the logic of social complexity. For this reason, comparative analysis that transcends ethnocentric visions is an adequate and necessary research perspective both to raise awareness of diversity and to try to explain and understand our environment beyond our own categorisations (Beltrán 1985: 14-15). Scientific research and knowledge are evaluative, and hence essentially comparative. Comparison objectivises and relativizes knowledge. To compare is to show the similar and the different, it is to confront and oppose different and common realities that oblige us to reflect on the particular and general nature of the social.

The social sciences, in terms of research activity, are essentially comparative. We agree with several authors when viewing their origin, and specifically that of sociology, to have been intrinsically comparative. The contributions by Montesquieu, Tocqueville, Durkheim, Marx and Weber were based on comparative logic, which in itself was considered (implicitly or explicitly) to be the appropriate method with which to analyse social reality. It is with Stuart Mill (1843) where we find the first systematisation of the experimental comparative method.

Comparison is inherent to the practice of knowledge because it allows us to assess and establish similarities and differences between our units of analysis and, consequently, establish what general elements are relevant in order to derive a general theorisation of the mechanisms that make the social reality in question function. For this reason, all methods for producing and analysing information and all empirical social research resort at some point in the research process to the logic of comparison. Indeed, there is no shortage of criticism of comparison as a method or of its specific identity, such as Marradi (1991: 66), for example, when pointing out that "it does not make much sense to present comparison as a particular, alternative method of others, from science".

However, despite agreeing with some of these criticisms and understanding that comparison is central to research, it cannot be denied that there is a series of general, abstract and specific methodological features that can be identified in comparative research where this approach is employed, and theoretically grounded and systematised procedures are 
followed, for the production and analysis of comparative data (Sartori 1970). Since it is the nature of scientific research, referring to the comparative method or comparative analysis means we can define what specific aspects identify it as a research strategy in its own right. However, the applied comparative methodology shares logic and instruments that are also used in other types of research in the social sciences (Smelser 1976; Ragin 2014). For this reason, we should not think so much of a standalone method that is differentiated from all others, but of a particular form of design analysis (López-Roldán and Fachelli 2015: ch. 2) that configures what we identify not as "the comparative method" but a specific way of proceeding, which we qualify as "comparative methodology" to the extent that a comparative research objective is established in which a model and a coherent, grounded design analysis are built, and, as Ragin (2014) highlights, aimed to compare large macrosocial units. Fideli (1998) and Piovani and Krawczyk (2017) point out that comparative research is usually identified as a diversity of strategies that involve the contrasting of contexts as a common feature, thus meaning that the proposed methodology is recognised in comparative terms as a type of investigation. Hence, this monographic issue proposes the establishment of a comparison between different territories, and between countries in particular.

Regarding cross-country or transnational research, which is explicitly comparative and systematically uses comparable data from two or more nations, Kohn (1987) highlighted its importance and the indispensable need to generalise the findings and the validity of the interpretations derived from single-nation studies. We also need to review our own interpretations to take into account the international differences and inconsistencies that could never be discovered from researching a single nation, the author concluding that "My thesis is that cross-national research provides an especially useful method for generating, testing, and further developing sociological theory".

In comparative research, whether from a cross-national or cross-cultural point of view, the central problem, from a theoretical-methodological perspective, is that of equivalence, of what is common. One of the first problems refers to the very identification of the objects to be compared, for two objects can only be compared when they have at least one property in common (Fideli 1998: 9), which means the question of the conceptualisation that serves as the basis for comparison must first be solved theoretically and then operationally. That is, when the theoretical and methodological criteria are made explicit and substantiated, this enables the comparison and equivalence of what is compared in a systematic and complete investigation process with the aim of achieving the best, most valid and most reliable knowledge.

From the recognition of the plurality of methodological perspectives and beyond the contrapositions between variable-oriented or case-oriented methodologies, comparative research is a challenge in terms of the conceptualisation of diverse and complex social realities, so it will surely always be necessary to specify, rethink, redefine or build new concepts that integrate the comparative and complex. It is of interest here to consider the generation of "integrating concepts" (Estany 2019: 6) in comparative research as a theoretical-methodological strategy that can help transcend particularisms and make generalisations possible. The integration of concepts involves the inclusion of different items in categories that have an explanatory force that is not reducible to the sum of the parts. They are usually associated with idealisations that provide us with an understanding of reality beyond what each of us could achieve separately. Thus, the author writes: "Let's not forget that conceptualizing is including diverse objects in the same category, but with common characteristics. Language is an example of this, since when we refer to "fruit" we include various objects, from apple and orange to dates and blackberries, which we "integrate" into this category. The basis of scientific knowledge is to categorize phenomena, systematize 
and conceptualize them. In this sense, we can consider integrating concepts as an epistemological resource that justifies a certain form of categorization. These types of concepts could also be called "metacategories"'.

Following Colino (2009) when identifying the specificity of the comparative method, and in line with Lijphart (1971), Elder (1976) and Ragin (2014), we view it as the scientific-logical procedure used for the comparative analysis of the social reality of two or more macrosocial units that are justifiably selected as homogeneous or heterogeneous contexts of analysis in which to study the variation, whether in terms of similarities or differences (Przeworski and Teune 1970), between variables or relationships. These, moreover, can be observed at different levels of analysis, to arrive either at the verification of hypotheses and explanatory causal propositions of general validity, or at the interpretation of different specific causal patterns in each case. The central issue is, as Sartori (1970) points out, to have a theoretical and conceptual framework that explicitly encompasses the units of analysis for which a research methodology is systematised in order to explain, while controlling for possible sources of variation in a certain social phenomenon. Therefore, following Elder (1976: 215-218), given the particularities and uniqueness that the cultural, socio-historical or institutional context confers, for example when comparing countries, theoretical-methodological rigour should preside over scientific practice and assess the relevance, benefits and limitations of any strategy and research outcome. In this study, it is assumed that researchers that seek transnational similarities and comparability generally share a common premise, that is, that "social forms and social processes are not confined within national or temporal borders." For this reason, the greatest interest of comparative research resides in the possibility of elaborating theoretical formulations that transcend a society's borders (Holt and Turner 1970: 6).

\section{Contributions to This Special Issue}

In this special issue we have selected the 13 papers presented below. We have organised the contributions by theme. It should be noted, first of all, that all articles apply a quantitative methodology. In turn, the various issues mentioned in the previous section on comparisons are addressed in one way or another in these papers. The possibility of making comparisons between similar or different countries is highlighted in the papers. But they also provide relevant information on certain limitations of such comparisons, even between countries considered "similar".

The selected contributions are presented in five major thematic blocks:

1. Assessments and perceptions of social status and identity, with three contributions;

2. Labour market, with five contributions;

3. Gender, care and family policies, with two contributions;

4. Towards the EU 2020 Strategy, with two contributions, and

5. Other comparative topics that include one paper on the social transfer effect and another on feelings of social insecurity with regard to crime.

We very briefly present the content of papers and also summarise the main characteristics in two tables that detail the authors, topic, unit of analysis, spatial and temporal delimitation, data source and main data analysis techniques of each contribution. 


\section{(1) Assessments and perceptions of social status and identity}

The paper "Being Poor and Feeling Rich or Vice Versa? The Determinants of Unequal Income Positions in Old Age Across Europe" by Bettina Isengard and Ronny König investigates the relationship between the objective income positions of older Europeans (aged $50+$ years) and their perception of their financial situation. To deal with this topic, the authors use the seventh wave of the Survey of Health, Aging, and Retirement in Europe (SHARE) conducted in 2017. The results show that objective income positions can be congruent with subjective self-perceptions of one's income situation, both good (well-being) and bad (deprivation). In analysing the causes of the two forms of nonconformance-adaptation (satisfaction paradox) and dissonance (dissatisfaction dilemma) — they conclude that sociodemographic and socioeconomic determinants alone cannot account for discrepancies. The variation can be observed in the consideration of certain social psychological influences or personality traits and especially in social comparison processes (with one's past) that are essential for explaining both the satisfaction paradox and the dissatisfaction dilemma.

The article "Social Capital and Subjective Social Status: Heterogeneity within East Asia" by Ji Hye Kim and Claire Seungeun Lee addresses the direct connections between social capital and subjective social status and highlights social capital as an essential source of subjective social status, particularly in East Asia. By analysing Chinese, Taiwanese, Korean, and Japanese samples from the 2012 East Asian Social Survey, the authors examine bonding, bridging, and cognitive dimensions of social capital and their connections to subjective perceptions of social status. The results show that individuals who develop wider social connections with people occupying high-status occupations tend to rank themselves higher on a subjective social-status scale in Chinese society only, where social connections play a particularly important role. Having trustworthy friends and relatives is associated with higher subjective social status in Taiwan and Korea. Finally, none of the social capital measures matter in Japan, the most individualistic society in East Asia.

The paper "European identity — an analysis of measurement equivalence across countries and mode of data collection in the European Values Survey 2017/2018" by Malina Voicu and Ioana Ramia analyses European Identity among people living in Europe. The authors introduce a new focus by defining the European Identity as an ethnic/cultural one as opposed to a civic identity, and they analyse the measurement equivalence of the scale topping European ethnic/cultural identity yielded by the European Values Survey in 2017 in 30 European countries. The results show a common understanding of Europeanness among people living in Europe in ethnic terms, but not in cultural ones. Methodologically, the analyses proved that the scale is suitable for cross-national comparisons among countries, but the comparability should be restricted in some counties. The mode of data collection does not have any impact on the comparability of the scale in four of the six countries that used mixed modes of data collection.

\section{(2) Labour market}

The paper "Assessing Youth Labour Market Integration across European regions" by Rosario Scandurra, Ruggero Cefalo and Yuri Kazepov links the territorial disparities and youth labour markets by presenting a composite measure of Youth Labour Market Integration (YLMI) that covers a wide range of indicators and sheds light on the EU territorial divide in opportunities for young people at a regional level. In order to build the YLMI index, 
the authors use benefit-of-the-doubt-weighting, a seminal methodology on composite indicators that combines sequence with conditional weights based on the range of each subindicator. To prove the usefulness of YLMI, the evolution of regional integration of young people in the labour market in the EU before and after the economic crisis is presented. Furthermore, they investigate the extent to which labour conditions, skills supply and technological resources explain cross-regional variations in the integration of young people in the labour market.

The paper "Comparing Precarious Employment Across Countries-Measurement Invariance of the Employment Precariousness Scale for Europe (EPRES-E)" by Eva Padrosa, Mireia Bolíbar, Mireia Julià and Joan Benach compares precarious employment across countries, assessing measurement invariance with an adaptation of the EPRES European scale, constructed as part of the European Working Conditions Survey (EWCS). The EPRES-E (the new measure) is composed of 13 proxy-indicators sorted into six dimensions: temporariness, disempowerment, vulnerability, wages, exercise of rights and unpredictable working times. The results show that threshold invariance holds for the firstorder structure (dimensions) in 22 of the 35 countries analysed, but only metric invariance is attained by the second-order structure, suggesting that precarious employment is configured by different sources within the six dimensions in each country according to their broader socio-political trajectory. The authors conclude that the new indicator can be used for comparative purposes in 22 European countries, but the scores for each dimension must be reported alongside the overall one.

The paper "Measuring labour market segmentation for a comparative analysis among countries" by Pedro López-Roldán and Sandra Fachelli addresses labour market segmentation and compares Spain and Argentina in order to understand the extent to which they generate similar dynamics in terms of the structure of labour inequalities. The authors' main objective is to construct an analysis model to study inequalities in the labour market in comparative terms that can be extended to other countries of Europe and Latin America. Their general hypothesis it that there is no single labour market that adjusts supply and demand, but that several segments can be expected to structure similar hierarchical positions in the labour market in line with specific labour supply profiles. As a second objective, the authors propose the application of a methodology to obtain two synthetic measures of labour market segmentation: first, a categorical measurement using a typology constructed from hierarchical positions and profiles using multivariate techniques (combining multiple correspondence factor analysis and cluster analysis); and second, a continuous measurement based on the results of factor analysis, the outcome being a composite indicator of labour inequality.

The paper "So far, so similar? Labour market feminization in Italy and Chile" by Renata Semenza, Giorgio Boccardo and Simone Sarti analyses gender segregation in the labour market while comparing two national contexts in Europe and Latin America: Italy and Chile. Specifically, they consider the growth trends in female employment in the last 25 years (1992-2017), its distribution between activity sectors and occupations, and the gender pay gap. The authors use labour market segmentation theories to frame feminisation models and gender inequalities, thus contrasting human capital theories and neoclassical economics. Following the hypothesis that the gender distribution of occupations measured by a segregation index is similar in Italy and Chile, the authors shed light on women's labour market conditions and segregation patterns, which are multidimensional and generalizable (transcontinental) phenomena, connected to the unequal division of labour in the new post-industrial order.

The following table summarises the proposals in the first and second block (Table 1). 


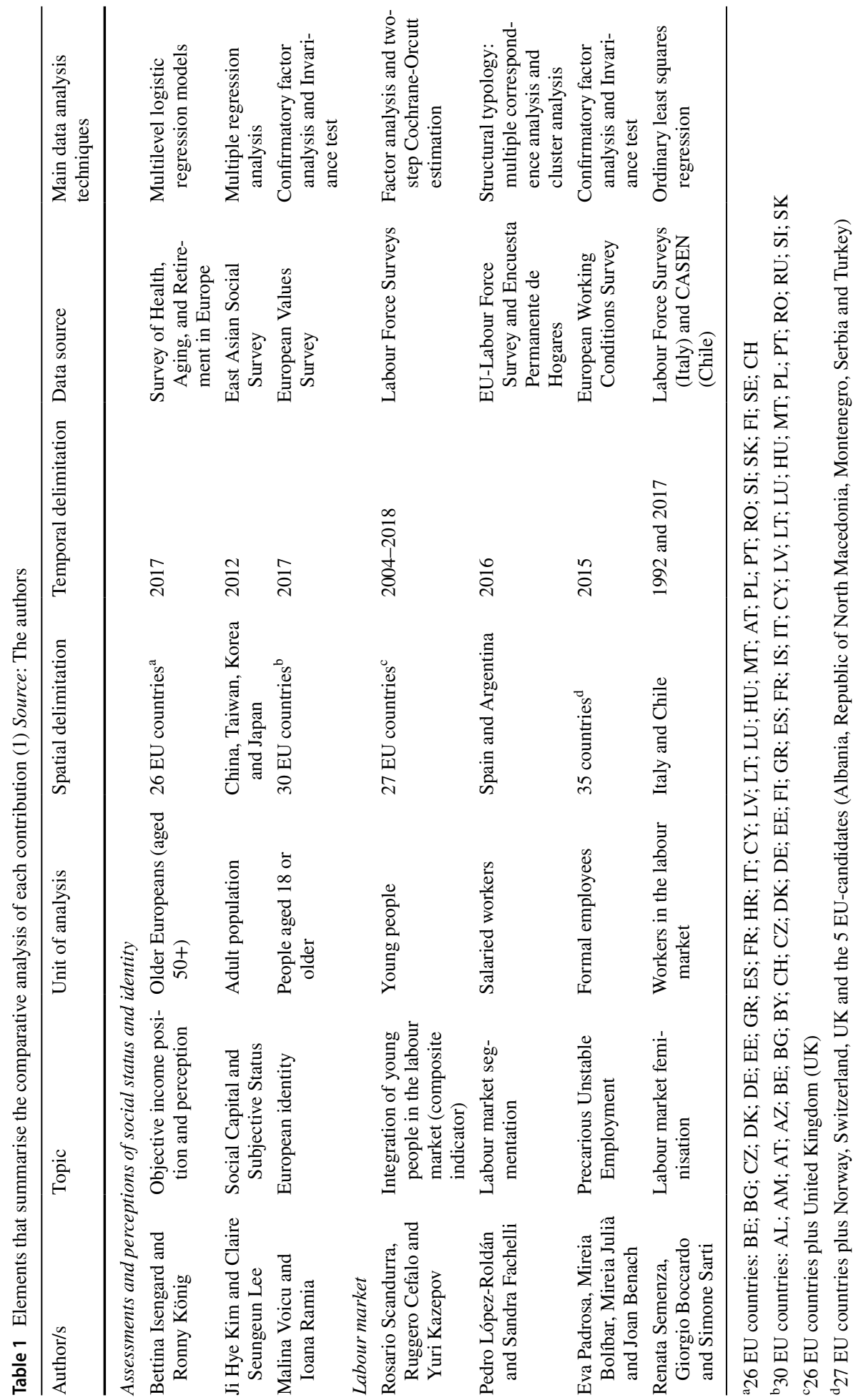


(3) Gender, care and family policies

The paper "Back to the future: a sensitivity analysis to predict future fertility rates considering the influence of family policies. The cases of Spain and Norway" by Vicente Díaz Gandasegui, Begoña Elizalde San-Miguel and Maria Teresa Sanz García analyses the relationship between family policies focused on childcare for children under the age of three and fertility levels. The analysis was carried out using Eurostat indicators and a stochastic dynamic mathematical model that incorporates both demographic variables and family policy variables on Spain and Norway, two countries that have very different family policies. The relationship between the existing family policies and the total fertility rate are established as well as the expected evolution of fertility rates in the future (should the current family policies remain constant). The results show that the models that lead to an increase in fertility are those that are most generous, and which also incorporate a gender perspective, and hence identify good practices and maximum levels of policy efficiency. In contrast, models with insufficient support contribute to maintaining fertility at very low levels and perpetuate unequal gender relationships.

The paper "Gender Gaps in Care Work: Evidence from Argentina, Chile, Spain, and Uruguay" by Marius Domínguez-Amorós, Karina Batthyány and Sol Scavino analyses gender gaps in the non-paid domestic and care work (NPDCW) undertaken in households in Argentina, Chile, Spain, and Uruguay. The authors take into account two-income households and their magnitude and impact on the distribution of NPDCW, which they analyse using data from national time use surveys. The study shows the importance of approximations of gender roles and its analyses incorporate macro-sociological factors. The findings show that NPDCW is done by women in $70 \%$ of cases and that the equalising effects of time availability and gender ideology are stronger for women in more egalitarian countries; but women in less egalitarian countries benefit less from their individual-level assets. The authors therefore show that changes in individual-level factors alone may not be enough to achieve an equal division of labour in the household without a parallel reduction in macrolevel gender inequality.

\section{(4) Towards the EU 2020 Strategy}

The paper "Lead and Lag Times of Countries in a Gentler World" by Oliver Nahkur and Rein Taagepera measures the rate at which the world has become gentler using four crossnationally comparable indicators based on six waves of the World Value Survey data from 25 countries between 1989 and 2014. They use four indicators-Welzel's Emancipative Values Index and Gender Equality sub-index, Locus of Control and Nahkur's Societal Index of Interpersonal Destructiveness (SIID) and also discuss their implications for the future. The authors observe a positive trend in these four indicators. Lead/lag times of individual countries often fluctuate by 20 or even 30 years. The average lag time was that found for Russia, Ukraine and Moldova. The average lead time was that of Sweden and Norway, and the only region where index values rise in a relatively steady manner is Central East Europe; but it is not certain that this rise has continued since 2012. 
The paper "Proposal for a dynamic composite indicator: application in a comparative analysis of trends in the EU member states towards the Europe 2020 Strategy" by M. Isabel Landaluce-Calvo and Mariola Gozalo-Delgado proposes the creation of a comparable composite indicator to assess the member states in terms of their achievement of the objectives proposed by the Europe 2020 Strategy. The originality of the study lies in the combination of three dimensions of information for analysis: observations, variables, and units of time. They use different Eurostat indicators in a study from 2009 to 2018. The empirical work visualises and quantifies differences and similarities in trends across the member states both collectively and individually, for all the variables and years selected for analysis, while also producing a Global Dynamic Indicator of the trends of the EU member states towards the targets set by the 2020 Strategy.

\section{Other comparative topics: social transfer effect and feelings of social insecurity}

The paper "Antipoverty effects of various social transfers and income taxes across countries" by Koen Caminada, Kees Goudswaard, Chen Wang and Jinxian Wang analyses the effectiveness of social transfers and income taxes for alleviating poverty. The authors assess 49 countries using micro-data from the Luxembourg Income Study (LIS) to examine the antipoverty effect of social transfers and income taxes. For their decomposition analysis, the authors apply a technique used by Kakwani in late eighties that calculates poverty rates without a certain kind of transfer or tax, and consequently the partial redistributive effect of that transfer or tax. Interesting findings include the one that $15 \%$ of the total population of all countries are lifted out of poverty via tax/benefit-systems and that there are three programmes that account for the majority of poverty reduction: old-age, disability and survivor scheme programmes.

The paper "Determinants of the Fear of Crime in Argentina and Brazil: A Cross-country Comparison of Non-Criminal and Environmental Factors Affecting Feelings of Insecurity" by Riccardo Valente and Mattia Vacchiano links the significance of non-criminal factors in explaining the fear of crime, such as socio-economic vulnerability, educational level and trust in people and institutions, as well as exposure to violence at one's place of residence. They compare the cases of Argentina and Brazil to assess which has the highest incidence of the fear of crime using a subset of the 2017 Latinobarómetro survey. Their results show that in Argentina, fears of crime are positively associated with socio-economic vulnerability and in turn are negatively associated with state-driven violence, while in Brazil the fear of crime is to a greater extent a consequence of previous victimisation and a general distrust in other people. The results also shed light on the problem of social cohesion in both countries, suggesting that the fear of crime is a social rather than a criminal issue.

The following table summarises the proposals from the last three blocks.

All that remains is to thank the authors for their efforts and for presenting the possibility to shed light on the different types of indicators and their potential use in comparative analysis between many countries and regions, thereby enriching analysis in this field (Table 2). 


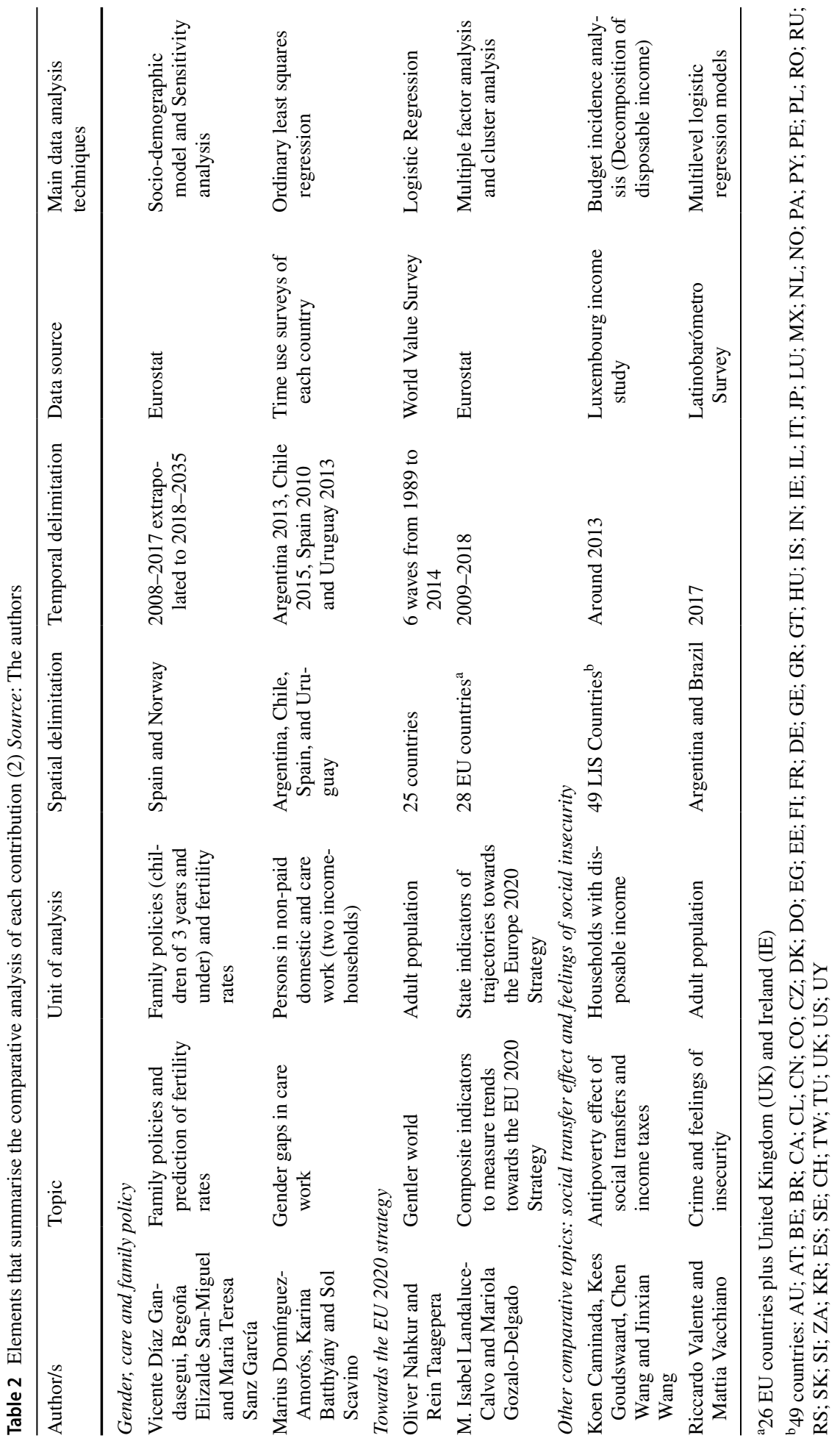




\section{References}

Beltrán, M. (1985). Cinco vías de acceso a la realidad social. Revista Española de Investigaciones Sociológicas, 29, 7-41.

Colino, C. (2009). Método comparativo. En Román Reyes (dir.), Terminología Científico-Social. Aproximación Crítica. Madrid-México: Ed. Plaza y Valdés. https://webs.ucm.es/info/eurotheo/diccionario/M/ metodocomparativo_a.htm.

Elder, J. W. (1976). Comparative cross-national methodology. Annual Review of Sociology, 2, 209-230.

Estany, A. (2019). Innovación y conceptos integradores en la práctica científica. Incasi Working Papers Series, 9. Dipòsit Digital de Documents. Bellaterra, Cerdanyola del Vallès (Barcelona). Universitat Autònoma de Barcelona. https://ddd.uab.cat/record/212718.

Fideli, R. (1998). La comparazione. Milano: Angeli.

Hantrais, L. (2009). International comparative research: Theory, methods and practice. Hampshire: Palgrave Macmillan.

Holt, R. T., \& Turner, J. E. (Eds.). (1970). The methodology of comparative research. New York: The Free Press.

Kohn, M. (1987). Cross-national research as an analytic strategy. American Sociological Review, 52(6), $713-731$.

Lijphart, A. (1971). Comparative politics and the comparative method. American Political Science Review, $65,682-693$

López-Roldán, P., \& Fachelli, S. (2015). Metodología de la Investigación Social Cuantitativa. Bellaterra (Cerdanyola del Vallès): Dipòsit Digital de Documents, Universitat Autònoma de Barcelona. $1^{\mathrm{a}}$ edición. Edición digital: http://ddd.uab.cat/record/129382

Marradi, A. (1991). Comparación. En Román Reyes (dir.), Terminología Científico-Social. Aproximación Crítica. Madrid: Anthropos (pp. 65-84).

Piovani, J., \& Krawczyk, N. (2017). Los estudios comparativos: Algunas notas históricas, epistemológicas y metodológicas. Educaçao and Realidade, 42(3), 821-840.

Przeworski, A., \& Teune, H. (1970). The logic of comparative social inquiry. New York: Wiley.

Ragin, Ch C. (2014). The comparative method: Moving beyond qualitative and quantitative strategies. Oakland, CA: University of California Press.

Sartori, G. (1970). Concept misformation in comparative politics. APSR, 4, 1033-1053.

Smelser, N. J. (1976). Comparative methods in the social sciences. Englewood Cliffs, NJ: Prentice-Hall.

Stuart Mill, J. (1843). A system of logic: Ratiocinative and inductive. Londres: John W. Parker.

Publisher's Note Springer Nature remains neutral with regard to jurisdictional claims in published maps and institutional affiliations. 